\title{
Oxidative stress in patients with endodontic pathologies
}

\author{
Veiko Vengerfeldt' \\ Reet Mändar ${ }^{2,3}$ \\ Mare Saag' \\ Anneli Piir ${ }^{2}$ \\ Tiiu Kullisaar ${ }^{2}$ \\ 'Institute of Dental Sciences, \\ Faculty of Medicine, University of \\ Tartu, ${ }^{2}$ Institute of Biomedicine \\ and Translational Medicine, Faculty \\ of Medicine, University of Tartu, \\ ${ }^{3}$ Competence Centre on Health \\ Technologies, Tartu, Estonia
}

This article was published in the following Dove Press journal: Journal of Pain Research

24 August 2017

Number of times this article has been viewed

Background: Apical periodontitis (AP) is an inflammatory disease affecting periradicular tissues. It is a widespread condition but its etiopathogenetic mechanisms have not been completely elucidated and the current treatment options are not always successful.

Purpose: To compare oxidative stress $(\mathrm{OxS})$ levels in the saliva and the endodontium (root canal $[\mathrm{RC}]$ contents) in patients with different endodontic pathologies and in endodontically healthy subjects.

Patients and methods: The study group of this comparison study included 22 subjects with primary chronic apical periodontitis (pCAP), 26 with posttreatment or secondary chronic apical periodontitis (sCAP), eight with acute periapical abscess, 13 with irreversible pulpitis, and 17 healthy controls. Resting saliva samples were collected before clinical treatment. Pulp samples (remnants of the pulp, tooth tissue, and/or previous root filling material) were collected under strict aseptic conditions using the Hedström file. The samples were frozen to $-80^{\circ} \mathrm{C}$ until analysis. OxS markers (myeloperoxidase [MPO], oxidative stress index [OSI], 8-isoprostanes [8-EPI]) were detected in the saliva and the endodontium.

Results: The highest MPO and 8-EPI levels were seen in pCAP and pulpitis, while the highest levels of OSI were seen in pCAP and abscess patients, as well as the saliva of sCAP patients. Controls showed the lowest OxS levels in both RC contents and saliva. Significant positive correlations between OxS markers, periapical index, and pain were revealed. Patients with pain had significantly higher OxS levels in both the endodontium (MPO median $27.9 \mathrm{vs} 72.6 \mathrm{ng} / \mathrm{mg}$ protein, $p=0.004$; OSI 6.0 vs $10.4, p<0.001 ; 8$-EPI 50.0 vs $75.0 \mathrm{pg} / \mathrm{mL}, p<0.001$ ) and saliva (MPO 34.2 vs $117.5 \mathrm{ng} / \mathrm{mg}$ protein, $p<0.001 ; 8$-EPI $50.0 \mathrm{vs} 112.8 \mathrm{pg} / \mathrm{mL}, p<0.001$ ) compared to pain-free subjects.

Conclusion: $\mathrm{OxS}$ is an important pathomechanism in endodontic pathologies that is evident at both the local (RC contents) and systemic (saliva) level. OxS is significantly associated with dental pain and bone destruction.

Keywords: apical periodontitis, irreversible pulpitis, oxidative stress, dental pulp cavity, saliva

\section{Introduction}

Apical periodontitis (AP) is an inflammatory disease affecting periradicular tissues and accruing from bacterial infection of dental pulp. It is the most frequent sequela of untreated dental caries and frequently results in tooth loss. AP is a widespread condition $^{1-3}$ that has a considerable effect on quality of life and that is a cause of significant health-related costs. The principal aim of endodontic treatment is to eliminate microorganisms from the root canal (RC) system before RC filling; however, the total elimination of RC biofilm can in some cases be close to impossible. Meanwhile, in some cases, AP
Institute of Biomedicine and Translational

Medicine, Faculty of Medicine, University of Tartu, Ravila 19, Tartu 504I I, Estonia $\mathrm{Tel}+3727374178$

Fax +3727374172

Email reet.mandar@ut.ee 
is found to heal even in the case of poor quality root canal treatment (RCT), while in other cases, signs of persistent AP can remain in spite of excellent $\mathrm{RCT}^{4}$ Thus, the etiopathogenetic mechanisms of AP have not been completely elucidated and the current treatment options are not always successful. ${ }^{5,6}$ Additional research is, therefore, urgently needed.

The generation of reactive oxygen species (ROS) is a major pathogenic mechanism for diseases involving phagocytic infiltration and bone resorption as host defense mechanisms against the invading pathogen. ${ }^{7}$ ROS are capable of triggering reactions in which radicals react with other organic molecules, resulting in oxidative damage. At the same time, the human body has developed antioxidant defense mechanisms involving a number of enzymatic and nonenzymatic systems, such as the peroxidase system, certain proteins, vitamins, uric acid, etc. The latter has been characterized as the most important antioxidant molecule found in saliva. An imbalance in favor of prooxidants is termed oxidative stress $(\mathrm{OxS}){ }^{8,9}$

Although research on the role of ROS and the protective capacity of salivary antioxidants in marginal periodontitis has been extensive, ${ }^{10}$ very few studies have been carried out concerning the associations between OxS and AP. These studies have described the prooxidant status in apical lesions of AP patients ${ }^{7}$ and influence of endodontic treatment on systemic OxS. ${ }^{9}$ To our knowledge, no studies investigating the role of excessive $\mathrm{OxS}$ and the salivary antioxidant system in the pathogenesis of AP have presented a comparison of OxS levels in saliva and the endodontium.

The aim of our comparison study was to collate the OxS levels in the saliva and the endodontium ( $\mathrm{RC}$ contents) in patients with different endodontic pathologies and in endodontically healthy subjects.

\section{Patients and methods}

\section{Study subjects and clinical examination}

One of the authors (VV) recruited randomly patients with endodontic pathology and healthy controls between January
9, 2015 and August 19, 2016 from the Clinic of Stomatology at University of Tartu, Estonia and a private dental clinic Kaselo Dental Clinic in Põltsamaa, Estonia. There was no difference between the patient contingents since adult patients have to pay for their dental care in Estonia in both settings. In addition, inclusion and exclusion criteria were similar in both clinics (Table S1) and all the patients were recruited by the same dentist (VV). Altogether, 124 subjects were initially recruited. From 86 subjects a sufficient amount of specimens for all biochemical studies was available; therefore, the final study group included 86 subjects, 69 with and 17 without endodontic pathology (Table 1, Figure S1).

Clinical examination of patients was performed as described previously. ${ }^{11}$ Endodontic pathology was diagnosed according to the current suggestions. ${ }^{12,13}$ Using a Kodak 2100 Intraoral X-Ray System (Carestream Dental, Rochester, NY, USA), an experienced radiologist or dentist (VV) took periapical radiographs with a Carestream 6100 sensor (Carestream Dental), using the long-cone paralleling technique for extension cone paralleling devices (Rinn Co, Elgin, IL, USA). Periapical radiographs were analyzed using Carestream Dental Imaging Software (Carestream Dental). Periapical index (PAI) was determined as described previously. ${ }^{14}$

Out of 69 patients with endodontic pathology, 22 had AP (periapical radiolucency) without previous RCT (primary chronic apical periodontitis [pCAP]) in at least one tooth, while 26 patients had AP (visible periapical radiolucency) with previous RCT done more than 4 years ago (posttreatment or secondary chronic apical periodontitis [sCAP]) in at least one tooth (the condition termed "sCAP" in this paper and in a previous paper ${ }^{11}$ is elsewhere also called posttreatment apical periodontitis ${ }^{15}$ and persistent apical periodontitis ${ }^{5}$ ). Acute periapical abscess was diagnosed in eight patients and symptomatic irreversible pulpitis with normal periapical tissues in 13 patients. The 17 control subjects were in good general health without any illness, they had intact teeth (all teeth were caries free; no sign of pulpitis, apical,

Table I Age and gender distribution of study subjects

\begin{tabular}{|c|c|c|c|c|c|c|c|}
\hline Group & No of subjects & No of men & No of women & Age (mean \pm SD) & Age range & PAI & Pain \\
\hline PCAP & 22 & $10(45 \%)$ & $12(55 \%)$ & $48.5 \pm 14.9$ & $20-76$ & $4.3 \pm 0.78$ & 17 (77\%) \\
\hline sCAP & 26 & II (42\%) & $5(58 \%)$ & $38.2 \pm 12.9$ & $21-70$ & $3.8 \pm 0.96$ & $10(39 \%)$ \\
\hline Abscess & 8 & $4(50 \%)$ & $4(50 \%)$ & $41.0 \pm 19.9$ & 18-83 & $5.0 \pm 0.00$ & $8(100 \%)$ \\
\hline Pulpitis & 13 & $5(38 \%)$ & $8(62 \%)$ & $37.1 \pm 9.6$ & $22-48$ & $1.2 \pm 0.44$ & $13(100 \%)$ \\
\hline Control & 17 & $6(35 \%)$ & II (64\%) & $28.5 \pm 13.1$ & $|8-6|$ & $1.0 \pm 0.00$ & $0(0 \%)$ \\
\hline Total & 86 & $36(42 \%)$ & $50(58 \%)$ & $38.7 \pm 14.0$ & $18-83$ & & $48(56 \%)$ \\
\hline
\end{tabular}

Note: Pain represent current pain or pain in recent anamnesis.

Abbreviations: PCAP, primary chronic apical periodontitis; sCAP, secondary chronic apical periodontitis; PAI, periapical index; SD, standard deviation. 
or marginal periodontitis was visible), and the analyzed 17 control teeth were totally intact wisdom or premolar teeth that were extracted due to prophylactic or orthodontic indications (Figure S1). The teeth affected by AP were all intact (crown and root[s] still present). All the patients in question presented with a single lesion with a radiographic diameter of $<2 \mathrm{~cm}$ that had no effect on anatomical structures, such as the maxillary sinus or the inferior alveolar nerve.

Exclusion criteria included recent (within 3 months) systemic or local treatment that could affect the results (eg, treatment with anti-inflammatory or antibiotic medicines), systemic inflammatory or metabolic diseases, smoking, obesity, pregnancy, and poor oral hygiene.

\section{Ethical considerations}

Participation in the study was voluntary. All subjects were briefed on the purpose of the study and entered the study after signing an ethics committee-approved informed consent form. The study was conducted according to the ethical principles for medical research involving human subjects set out in the Declaration of Helsinki and approved by the Ethics Review Committee on Human Research of the University of Tartu (protocol no 195/T-11). All collected data were coded and isolated; personal data and measurement data were kept separately.

\section{Sample collection}

Resting saliva samples were collected and handled before clinical treatment as described previously. ${ }^{16}$ All procedures related to the collection of saliva specimens were performed by the same investigator/dentist. The samples were frozen and stored at $-80^{\circ} \mathrm{C}$ until analysis.

Pulp samples were collected under strict aseptic conditions as described previously. ${ }^{11,17}$ Exactly 6 filing stokes from each tooth ( $\mathrm{RC}$ ) were done. If a tooth had more than one root, sampling was done from the more diseased root. Remnants of the pulp, tooth tissue, and/or previous root filling material were collected using the Hedström file (Dentsply/ Maillefer, Ballaigues, Switzerland). The file was advanced to the working length -the " 0 " mark in the electronic apex locator (Root ZX; Morita, Osaka, Japan) minus $0.5 \mathrm{~mm}$. The file was thereafter inserted into an Eppendorf tube containing $1 \mathrm{~mL}$ of phosphate-buffered saline as a transport medium. The tube was then vortexed until all the remnants from the file were loose, after which the file was removed from the tube. The samples were frozen to $-80^{\circ} \mathrm{C}$ until analysis.

Saliva and pulp samples for the measurement of 8-isoprostanes (8-EPI) were stored at $-80^{\circ} \mathrm{C}$ in the presence of $0.005 \%$ butylated hydroxytoluene $(10 \mu \mathrm{L}$ of $5 \mathrm{mg} / \mathrm{mL}$ solution in etha- nol per $1 \mathrm{~mL}$ sample) to avoid auto-oxidation before assay using the chosen method (kit no 516351; Cayman Chemical, Ann Arbor, MI, USA). ${ }^{18}$ Samples were thawed before the biochemical analyses, homogenized, and centrifuged for 15 minutes at $3000 \mathrm{rpm}$, and the supernatant removed for immediate analysis.

\section{Oxidative stress index (OSI)}

OSI is an indicator of the redox balance between oxidation and antioxidation. It is expressed as the ratio of total peroxide concentrations (TPX) to total antioxidant capacity (TAC). An OxyStat colorimetric assay kit (Biomedica, Wien, Austria; cat no BI-5007) was used for measuring TPX as described. ${ }^{19}$ TAC was measured using a colorimetric assay ${ }^{20}$ based on the decolorization of 2,2'-azinobis(3-ethylbenzothiazoline 6-sulfonate) radical action. Decolorization by antioxidants according to their concentration and antioxidant capacity is measured as the change in absorbance at $660 \mathrm{~nm}$. The assay was calibrated using Trolox (a soluble vitamin E analog). TAC values were expressed as an equivalent of the millimolar concentration of Trolox solution.

\section{Myeloperoxidase (MPO)}

A commercially available enzyme-linked immunosorbent assay kit (Biocheck, Foster City, CA, USA; cat no BC 1129) was used to determine MPO as described. ${ }^{21}$

\section{8-EPI}

A commercially available enzyme-linked immunosorbent assay (Cayman Chemical; kit no 516351) was used for the measurement of 8-EPI as described. ${ }^{18}$ The assay used is based on the competition between an 8-EPI-acetylcholinesterase (AChE) conjugate (8-EPI tracer) and 8-EPI for a limited number of 8 -EPI-specific rabbit antiserum binding sites. The concentration of 8-EPI varies while the concentration of 8-EPI tracer is kept constant. The amount of 8-EPI tracer capable of binding to the rabbit antiserum is inversely proportional to the concentration of 8-EPI in the well. The resulting rabbit antiserum-8-EPI (either free or tracer) complex binds to the rabbit IgG mouse $\mathrm{mAb}$ previously attached to the well. The plate is then washed to remove any unbound reagents, after which Ellman's reagent (containing the substrate to $\mathrm{AChE}$ ) is added to the well. The product of this enzymatic reaction is yellow in color and absorbs strongly at $412 \mathrm{~nm}$. The intensity of this color is proportional to the amount of 8-EPI tracer bound to the well.

\section{Statistical analysis}

SigmaStat (Systat Software, Chicago, IL, USA) software was used for statistical analyses. Differences between the three 
groups were analyzed using Kruskal-Wallis one way analysis of variance on ranks. Spearman rank order correlation analysis was used to find associations between the markers. Criteria for significance were set at $p<0.05$ for all parameters.

\section{Results}

The study included a total of 86 subjects, 50 of whom were women and 36 men. The mean age of the patients was $38.7 \pm 14.0$ years (youngest 18 , oldest 83 years). Clinical data of the study subjects are presented in Table 1.

$\mathrm{OxS}$ levels in the endodontium and saliva were assessed using MPO, OSI, and 8-EPI. In total, MPO levels were higher in saliva than in the endodontium (median 100.8 vs 55.3 , $p<0.001$ ), while no significant differences between saliva and the endodontium were found in OSI and 8-EPI.

A

8-EPI

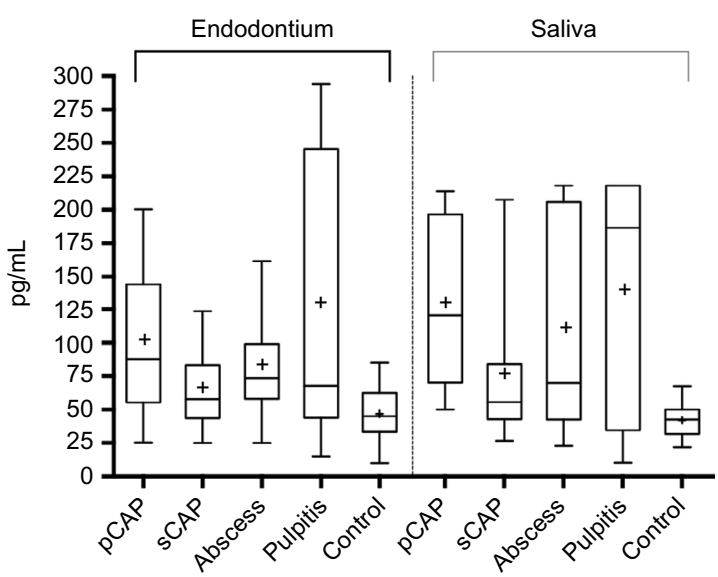

The highest MPO and 8-EPI levels were seen in the case of pCAP and pulpitis, in both endodontium and saliva, while in SCAP and abscess patients these markers tended to display lower values (Figure 1). The highest levels of OSI were seen in pCAP and abscess patients, in saliva also in SCAP patients. The control group showed the lowest levels of all OxS markers in both the endodontium and saliva.

OxS markers were positively correlated with each other both in the endodontium (MPO and OSI: $r=0.21, p=0.048$; MPO and 8-EPI: $R=0.28, p=0.008$; OSI and 8-EPI: $r=0.27$, $p=0.012$ ) and saliva (MPO and OSI: $r=0.31, p=0.003$; MPO and 8-WPI: $r=0.33, p=0.002$ ). Positive correlations were also seen between MPO detected in saliva and the endodontium $(r=0.63, p<0.001)$ and between 8-EPI detected in saliva and endodontium $(r=0.33, p=0.002)$.

B

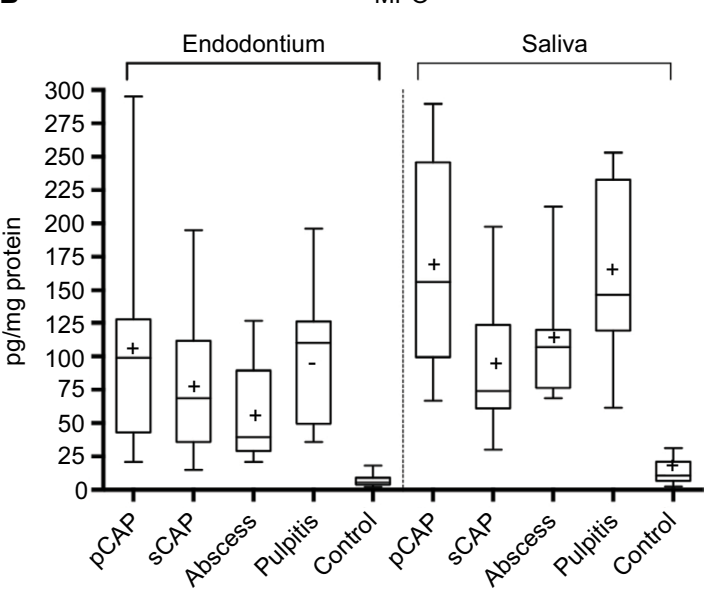

OSI

C

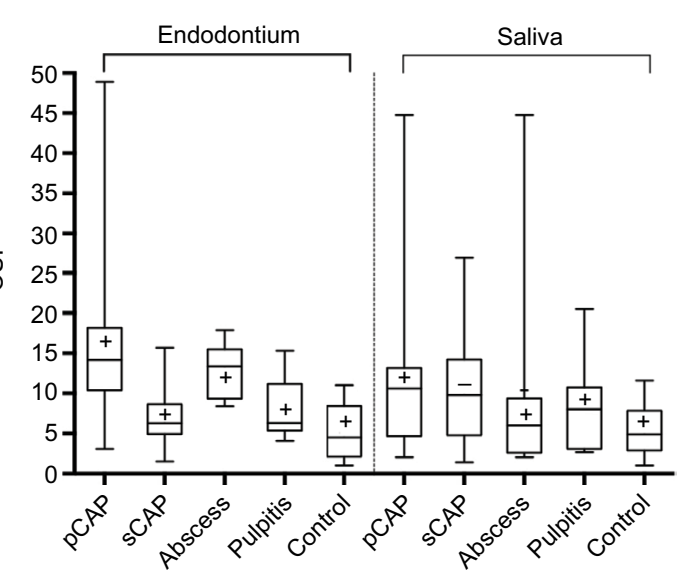

Figure I Box plot illustrating the distribution of oxidative stress parameters in different patient groups.

Notes: (A) 8-EPI; (B) MPO; (C) OSI. Box plot explanation: upper horizontal line of box, 75th percentile; lower horizontal line of box, 25th percentile; horizontal bar within box, median; upper and lower horizontal bars outside box, range. + represents means.

Abbreviations: 8-EPI, 8-isoprostanes; MPO, myeloperoxidase; OSI, oxidative stress index; PCAP, primary chronic apical periodontitis; sCAP, secondary chronic apical periodontitis. 
Positive associations of PAI and pain (current pain or pain in recent anamnesis) with OxS markers are shown in Figure 2. PAI and pain were also positively correlated $(r=0.43, p<0.001)$. Patients with pain had significantly higher OxS levels in both the endodontium and saliva in comparison with pain-free subjects (Table 2). Putative associations between local and systemic $\mathrm{OxS}$ and pain in AP patients are shown in Figure 3.

\section{Discussion}

Our study revealed that $\mathrm{OxS}$ is an important pathogenetic mechanism in several endodontic pathologies, such as primary and secondary AP, periapical abscess, and pulpitis. All these patients displayed significantly higher OxS levels, in

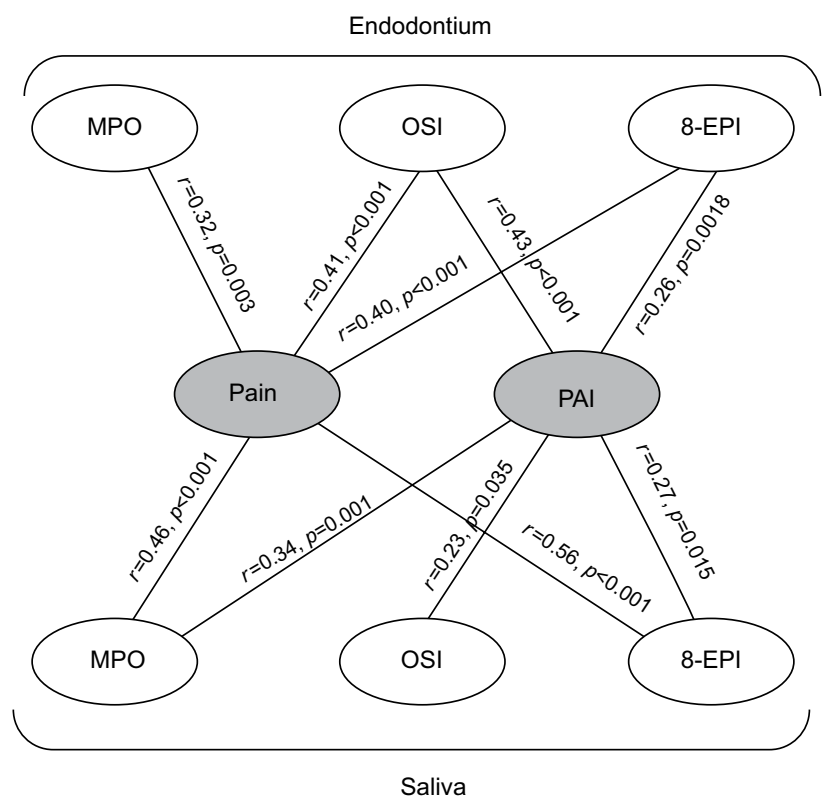

Figure 2 Correlations between clinical and biochemical markers.

Notes: Spearman's rank order correlation was used. Pain refers to the current pain or pain in recent anamnesis.

Abbreviations: MPO, myeloperoxidase; OSI, oxidative stress index; 8-EPI, 8-isoprostanes; PAI, periapical index. both the endodontium and saliva, than healthy controls. We also showed that $\mathrm{OxS}$ is significantly associated with some clinical markers, such as pain and PAI. To the best of our knowledge, this is the first study describing both local and systemic OxS levels in different endodontic pathologies.

AP represents an important host defense response aiming to confine $\mathrm{RC}$ bacteria and prevent them from spreading into adjacent bone and other surrounding tissues. Different inflammatory mediators have been associated with this condition. Though not always, the lesions can be accompanied by clinical symptoms, such as pain, tenderness, and swelling. Tissue destruction in the form of periapical bone resorption occurs as a part of the defensive process. When bacteria are eliminated by RCT, the active inflammatory lesion gradually reduces in size, usually accompanied by bone regeneration. ${ }^{22,23}$ At the same time, the inflammation is always associated with the generation of ROS at the cellular level as well as in biofluids. A difference between local inflammation and $\mathrm{OxS}$ in tissues (the endodontium, connective tissue) and systemic OxS in saliva can be observed. OxS levels depend on one hand on the bacterial infection-related inflammation and on the other

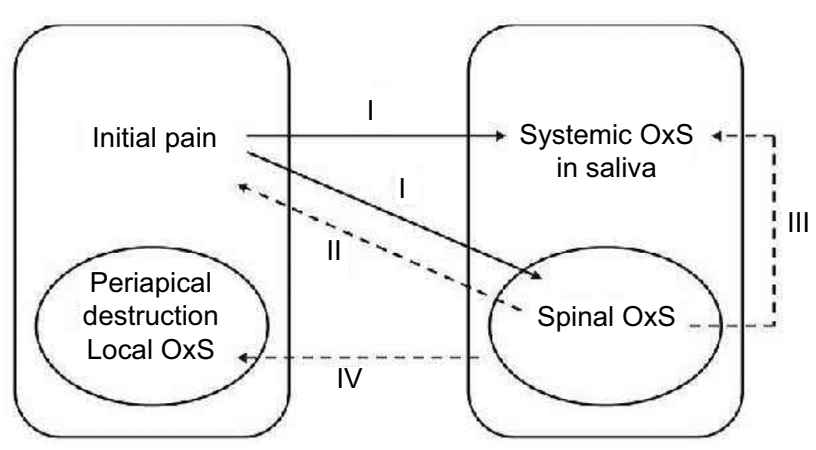

Figure 3 Putative associations between OxS and pain in apical periodontitis. Notes: I: peripheral stimuli - initial pain may lead to spinal and systemic OxS. II: spinal OXS (OxS on the level of the spinal cord) is a sufficient cause of pain. ${ }^{37} \mathrm{III}$ : spinal OxS contributes to systemic OxS. IV: systemically generated 8-isoprostanes could contribute to the periapical OxS as well as bone destruction and pain. ${ }^{23}$ Abbreviation: OxS, oxidative stress.

Table 2 Oxidative stress parameters and PAI in the presence and absence of pain, median (quartiles)

\begin{tabular}{|c|c|c|c|}
\hline & No pain & Pain\# & p-value* \\
\hline \multicolumn{4}{|l|}{ Endodontium } \\
\hline PAl & $2.0(1.0-4.0)$ & $4.0(2.0-5.0)$ & $<0.001$ \\
\hline MPO (ng/mg protein) & $27.9(5.6-100.9)$ & $72.6(39.2-111.2)$ & 0.004 \\
\hline OSI & $6.0(3.6-8.9)$ & $10.4(6.6-\mid 4.9)$ & $<0.001$ \\
\hline 8-EPI (pg/mL) & $50.0(36.0-67.5)$ & $75.0(56.1-122.4)$ & $<0.001$ \\
\hline \multicolumn{4}{|l|}{ Saliva } \\
\hline MPO (ng/mg protein) & $34.2(11.1-126.0)$ & II 7.5 (76.0-190.9) & $<0.00$ I \\
\hline OSI & $7.2(4.1-12.0)$ & $8.0(3.6-10.6)$ & NS \\
\hline 8-EPI (pg/mL) & $50.0(35.0-55.0)$ & I I 2.8 (60.3-2| 0.0$)$ & $<0.001$ \\
\hline
\end{tabular}

Notes: *Mann-Whitney rank sum test was used. ${ }^{\#}$ Current pain or pain in recent anamnesis.

Abbreviations: MPO, myeloperoxidase; OSI, oxidative stress index; PAI, periapical index; 8-EPI, 8-isoprostanes; NS, not significant. 
hand, the protective power of the antioxidative system. The highest MPO and 8-EPI levels in our study were detected in the case of pCAP and pulpitis, in both the endodontium and saliva, while both markers tended to display lower values in SCAP and abscess patients (Figure 1). OSI, the indicator of redox balance between oxidation and antioxidation, was expressed as the ratio of TPX to TAC. The highest OSI levels were seen in the RC of pCAP and abscess patients, as well as the saliva of SCAP patients. Free lipid concentrations are low in saliva because lipids are bound with proteins, and they are even lower in the endodontium, making them the probable cause of the variable values between the study groups. ${ }^{24}$ In addition, the TAC value may be compensatorily higher in the case of pulpitis, ${ }^{25}$ leading to lower OSI index values in these patients. The control group showed the lowest levels of all OxS markers in both the endodontium and saliva.

Prooxidant and antioxidant levels are normally balanced in the body, including the oral cavity. Low levels of ROS are needed for a number of biological functions, such as intracellular messaging, growth, cellular differentiation, and antibacterial activity. At the same time, increased production and/or reduced elimination of ROS could result in increased risk of oral diseases, while also having systemic implications, such as increased cardiovascular and neurodegenerative morbidity, as well as depressive symptoms. ${ }^{9,26,27}$ ROS are implicated in cell and tissue damage in various disorders by modifying and inactivating proteins, lipids, nucleic acids and inducing cellular dysfunctions. Injury and inflammation are associated with increased prostanoid synthesis and pain hypersensitivity. Prostanoids are considered to mediate inflammation and immune responses, as their administration produces hyperalgesia and other major signs of inflammation. ${ }^{28,29}$

Isoprostanes are stereoisomers of prostaglandins that are primarily formed through the nonenzymatic peroxidation of arachidonic acid by ROS..$^{30}$ The half-lives, stability, chemical properties, and affinity toward prostaglandin receptors of isoprostanes can vary, resulting in different bioactivity profiles. 8-EPI are relatively stable and are cleared with urine and other bioliquids, making them excellent markers of systemic OxS. Studies have indicated that electrophilic cyclopentenone isoprostane levels may be seven times higher than brain 8-EPI levels, but the former are not as chemically stable. ${ }^{31}$ Of lipid peroxidation products (LPP), isoprostanes are relevant for pain due to their ability to upregulate nociceptive pathways by stimulating prostanoid receptors. ${ }^{30}$ Highly reactive cyclopentenone prostaglandins and isoprostanes have been proposed as transient receptor potential cation channel, subfamily A, member 1 (TRPA1) agonists that can react with intracellular thiols including antioxidant glutathione and through cysteine binding. ${ }^{32,33}$

Studies indicate that a peripheral injury can cause sensitization associated with mitochondria-generated $\mathrm{OxS}$ in the dorsal horn of the spinal cord. ${ }^{34}$ Pain signaling begins by the activation of cell bodies of primary sensor afferents located in the dorsal horn ganglia, with one process reaching the periphery and another the spinal cord. Prostaglandins (isoprostanes) are likely to act on both terminals of these neuronal processes to induce hyperalgesia. This noxious stimulus opens the pain sensors coupled to ion channels, including TRPA1 and TRPV1, leading to the entrance of sodium and calcium into the cell, and following depolarization of the primary sensor afferent. ${ }^{35}$ It leads to the next stage of signal transmission - release of glutamate into synapses in the dorsal horn of the spinal cord. Neurons of the dorsal horn accept the signal by ionotropic glutamate receptors, including $\mathrm{N}$-methyl D-aspartate receptor and $\mathrm{Ca} 2+$-permeable $\alpha$-amino3-hydroxy-5-methyl-4-isoxazolepropionic acid receptor. The latter receptors support the influx of $\mathrm{Ca}$ into cells and into mitochondria increasing the level of superoxide. ${ }^{36,37}$ Because of the ionic disbalance in the mitochondrion ( $\mathrm{Ca}$ influx), the production of superoxide anions increases, which may generate dangerous hydroperoxyl radicals, the latter being capable of initiating the generation of lipid peroxides and $\mathrm{OxS}^{38}$

Peripheral stimuli (initial pain) may thus lead to spinal and systemic OxS (Figure 3, path I). Nociceptive primary afferents are capable of inducing a state of increased excitability in the dorsal horn neurons of the spinal cord. Increased generation of superoxide is a potential common characteristic of at least three pathogenetic pathways. Superoxide anion is a highly reactive oxygen radical implicated in cell and tissue damage related to various disorders, including inflammatory diseases. While superoxide production in neutrophils and other phagocytic cells is essential for killing microbes, it also leads to tissue damage at the inflammation site. Imbalance between the production and elimination of oxygen radicals in periapical lesions has been proposed as a factor in periapical damage and bone loss in chronic AP. ${ }^{39}$ In our study, OSI values were statistically significantly higher in $\mathrm{pCAP}$ and sCAP patients compared to controls, in both the endodontium and saliva. OSI also had a strong correlation with inflammation/bone loss (PAI) in the endodontium. Superoxide anion can be produced by osteoclasts and can play a part in bone resorption. It may also react with a precursor in plasma, resulting in the generation of a factor that is chemotactic for neutrophils. ${ }^{39}$ In addition to host cells, superoxide anion can also be produced in bacteria. For example, the production of 
superoxide by Streptococcus spp. has been shown to be lytic for erythrocytes, and extracellular superoxide production has been demonstrated to be a common trait for Enterococcus faecalis. ${ }^{39,40}$ Our measurements of total lipid peroxides/TAC showed that in the case of pCAP, the above-mentioned ratio was significantly higher in both the endodontium and saliva compared to controls.

Furthermore, spinal OxS (Figure 3, path II) has been shown to be a sufficient cause of pain. ${ }^{41}$ Spinal OxS can be the key factor linking pain-producing pathways. Pathway II is the positive feedback that may be mediated by electrophilic LPP capable of passing through the cell membrane by passive diffusion ${ }^{42}$ and therefore it can be a key link in pain-causing pathways. Additionally, LPP react with glutathione and if the level of the latter is low, electrophilic LPP are more toxic to proteins and nucleinic acids. Animal experiments have shown that the decrease of glutathione in the spinal cord induces pain. ${ }^{42,43}$

OxS on the level of the spinal cord contributes to systemic OxS in saliva (Figure 3, path III). Pathway III is mediated by LPP functioning as ligands of prostanoid receptors. These ligands include 8-EPI and prostaglandin F2 $\alpha$ (PGF2 $\alpha$ ). Peripheral 8-EPI and spinal PGF2 $\alpha$ may lead to sensitization, but prostanoid signaling is also a necessary step in converting short-term signaling to long-term changes in neuronal phenotype. ${ }^{44}$ This mechanism may provide additional support to the previously suggested idea that a sensitized state remains even after the initiating stimulus is lost. ${ }^{45}$

It has been suggested ${ }^{23}$ that systemically generated 8-EPI in saliva could contribute to periapical $\mathrm{OxS}$, as well as bone destruction and pain (Figure 3, path IV). Therefore, the generation of 8-EPI due to the chronic AP in saliva and $\mathrm{OxS}$ at the level of the spinal cord can result in positive feedback by irritating the primary afferents of the pulp. This is in line with our data where higher values of 8-EPI were seen in patients with pain and more severe bone destruction (higher PAI).

The used methodology included three different OxS markers that were used for both saliva (to reveal systemic OxS) and endodontium (to reveal local OxS). OSI is an indicator of the redox balance between oxidation and antioxidation being expressed as the ratio of TPX to TAC. MPO is a peroxidase enzyme stored in azurophilic granules of polymorphonuclear neutrophils and macrophages and released into the extracellular fluid in the setting of inflammatory process. It is characterized by powerful pro-oxidative and proinflammatory properties and its measurement can be used as an indication of neutrophil activation. 8-EPI are the major relatively stable end products of ROS-mediated prostanoid oxidation. They are released in response to cellular activation, circulate as a free form or as esters in phospholipids in plasma, and are excreted in urine. 8-EPI is acknowledged by the Society of Free Radical Research roundtable sessions as the best markers for the assessment of systemic OxS, allowing one to establish OxS-driven lipid peroxidation as well as nucleic acid damage. Limitations of our study include small sample size and the moderate list of biochemical markers. However, as this is the first study describing both local and systemic OxS levels in the case of different endodontic pathologies and as the differences between patients and controls appeared to be statistically different, we decided to present our results. Further studies are needed to confirm associations between $\mathrm{OxS}$ and endodontic pathologies.

In conclusion, $\mathrm{OxS}$ is an important pathological mechanism in endodontic diseases including pCAP and sCAP, periapical abscess, and pulpitis that is evident at both the local (RC contents) and systemic ( saliva) level. OxS is significantly associated with dental pain and bone destruction.

\section{Acknowledgments}

This study was supported by the Estonian Research Council (grant no IUT20-42 and IUT34-19), the European Union through the European Regional Development Fund (project no 2014-2020.4.01.15-0012), and Enterprise Estonia (grant no EU48695). The authors would like to thank Ms Merle Luht for excellent technical help.

\section{Disclosure}

The authors report no conflicts of interest in this work.

\section{References}

1. Huumonen S, Suominen AL, Vehkalahti MM. Prevalence of apical periodontitis in root filled teeth: findings from a nationwide survey in Finland. Int Endod J. 2017;50:229-236.

2. Di Filippo G, Sidhu SK, Chong BS. Apical periodontitis and the technical quality of root canal treatment in an adult sub-population in London. Br Dent J. 2014;216(10):E22.

3. Timmerman A, Calache H, Parashos P. A cross sectional and longitudinal study of endodontic and periapical status in an Australian population. Aust Dent J. Epub 2017 Mar 8.

4. Seltzer S, Bender IB. Cognitive dissonance in endodontics. J Endod. 2003;29:714-719.

5. Nair PN. On the causes of persistent apical periodontitis: a review. Int Endod J. 2006;39:249-281.

6. Siqueira JF Jr, Rôças IN. Community as the unit of pathogenicity: an emerging concept as to the microbial pathogenesis of apical periodontitis. Oral Surg Oral Med Oral Pathol Oral Radiol Endod. 2009;107: 870-878.

7. Dezerega A, Madrid S, Mundi V, et al. Pro-oxidant status and matrix metalloproteinases in apical lesions and gingival crevicular fluid as potential biomarkers for asymptomatic apical periodontitis and endodontic treatment response. J Inflamm (Lond). 2012;9:8.

8. Liskmann S, Vihalemm T, Salum O, Zilmer K, Fischer K, Zilmer M. Characterization of the antioxidant profile of human saliva in periimplant health and disease. Clin Oral Implants Res. 2007;18:27-33. 
9. Inchingolo F, Marrelli M, Annibali S, et al. Influence of endodontic treatment on systemic oxidative stress. Int J Med Sci. 2014;11:1-6.

10. D'aiuto F, Nibali L, Parkar M, Patel K, Suvan J, Donos N. Oxidative stress, systemic inflammation, and severe periodontitis. J Dent Res. 2010;89:1241-1246.

11. Vengerfeldt V, Špilka K, Saag M, et al. Highly diverse microbiota in dental root canals in cases of apical periodontitis (data of illumina sequencing). J Endod. 2014;40:1778-1783.

12. American Association of Endodontics. AAE consensus conference recommended diagnostic terminology. J Endod. 2009;35:1634.

13. Gutmann J, Baumgartner J, Gluskin A, Hartwell G, Walton RE. Identify and define all diagnostic terms for periapical/periradicular health and disease states. J Endod. 2009;35:1658-1674.

14. Orstavik D, Kerekes K, Eriksen HM. The periapical index: a scoring system for radiographic assessment of apical periodontitis. Endod Dent Traumatol. 1986;2:20-34.

15. Siqueira J Jr, Rôças I, Ricucci D, Hülsmann M. Causes and management of post-treatment apical periodontitis. Br Dent J. 2014;216:305-312.

16. Saliva Collection and Handling Advice. 3rd ed. Salimetrics LLC, Salivabio LLC. State College, PA, USA. 2015.

17. Fouad AS. Endodontic Microbiology. Baltimore: Wiley-Blackwell; 2009.

18. Dahl JH, Van Breemen RB. Rapid quantitative analysis of 8-iso- $\mathrm{PGF}_{2} \alpha$ using liquid chromatography-tandem mass spectrometry and comparison to an enzyme immunoassay method. Anal Biochem. 2010;404: 211-216.

19. Salum E, Kals J, Kampus P, et al. Vitamin D reduces deposition of advanced glycation end-products in the aortic wall and systemic oxidative stress in diabetic rats. Diabetes Res Clin Pract. 2013;100:243-249.

20. Erel O. A novel automated direct measurement method for total antioxidant capacity using a new generation, more stable ABTS radical cation. Clin Biochem. 2004;37:277-285.

21. Shen J, Platek M, Mahasneh A, Ambrosone C, Zhao H. Mitochondrial copy number and risk of breast cancer: a pilot study. Mitochondrion. 2010;10:62-68.

22. Bergenholtz G, Horsted-Bindslev P, Reit C. Textbook of Endodontology. Oxford: Wiley-Blackwell; 2013.

23. Eder A, Koegl E, Von Duvillard SP, Sinzinger H, Berent R. Influence of cigarette smoking on synthesis of eicosanoids, isoprostanes and lipoxygenase metabolites in apical periodontitis. Arch Oral Biol. 2012;57:1133-1140.

24. Tomita Y, Miyake N, Yamanaka S. Lipids in human parotid saliva with regard to caries experience. J Oleo Sci. 2008;57:115-121.

25. Tóthová L, Kamodyová N, Červenka T, Celec P. Salivary markers of oxidative stress in oral diseases. Front Cell Infect Microbiol. 2015;5:73.

26. Segura-Egea JJ, Martín-González J, Castellanos-Cosano L. Endodontic medicine: connections between apical periodontitis and systemic diseases. Int Endod J. 2015;48:933-951.

27. Gomes C, Martinho FC, Barbosa DS, et al. Increased root canal endotoxin levels are associated with chronic apical periodontitis, increased oxidative and nitrosative stress, major depression, severity of depression, and a lowered quality of life. Mol Neurobiol. Epub 2017 Apr 28.
28. Pradeep AR, Rao NS, Bajaj P, Agarwal E. 8-Isoprostane: a lipid peroxidation product in gingival crevicular fluid in healthy, gingivitis and chronic periodontitis subjects. Arch Oral Biol. 2013;58:500-504.

29. Materazzi S, Nassini R, Andre E, et al. Cox-dependent fatty acid metabolites cause pain through activation of the irritant receptor TRPA1. Proc Natl Acad Sci U S A. 2008;105:12045-12050.

30. Morrow JD. The isoprostanes - unique products of arachidonate peroxidation: their role as mediators of oxidant stress. Curr Pharm Des. 2006;12: 895-902.

31. Musiek E, Breeding R, Milne G, Zanoni G, Morrow J, Mclaughlin B. Cyclopentenone isoprostanes are novel bioactive products of lipid oxidation which enhance neurodegeneration. JNeurochem. 2006;97:1301-1313.

32. Taylor-Clark T, Undem B, Macglashan D Jr, Ghatta S, Carr M, Mcalexander MA. Prostaglandin-induced activation of nociceptive neurons via direct interaction with transient receptor potential A1 (TRPA1). Mol Pharmacol. 2008;73:274-281.

33. Nyman E, Franzen B, Nolting A, et al. In vitro pharmacological characterization of a novel TRPA 1 antagonist and proof of mechanism in a human dental pulp model. J Pain Res. 2013;6:59-70.

34. Schwartz E, Kim H, Wang J, et al. Persistent pain is dependent on spinal mitochondrial antioxidant levels. J Neurosci. 2009;29:159-168.

35. Pan Z, Yang H, Reinach PS. Transient receptor potential (TRP) gene superfamily encoding cation channels. Hum Genomics. 2011;5:108-116.

36. Wollmuth LP, Sakmann B. Different mechanisms of $\mathrm{Ca} 2+$ transport in NMDA and Ca2+-permeable AMPA glutamate receptor channels. J Gen Physiol. 1998;112:623-636.

37. Schwartz ES, Kim HY, Wang J, et al. Persistent pain is dependent on spinal mitochondrial antioxidant levels. J Neurosci. 2009;29:159-168.

38. Aikens J, Dix TA. Perhydroxyl radical (HOO.) initiated lipid peroxidation. The role of fatty acid hydroperoxides. J Biol Chem. 1991;266:15091-15098.

39. Graunaite I, Lodiene G, Maciulskiene V. Pathogenesis of apical periodontitis: a literature review. J Oral Maxillofac Res. 2011;2:e1.

40. Minczykowski A, Woszczyk M, Szczepanik A, Lewandowski L, Wysocki H. Hydrogen peroxide and superoxide anion production by polymorphonuclear neutrophils in patients with chronic periapical granuloma, before and after surgical treatment. Clin Oral Investig. 2001;5:6-10.

41. Schwartz E, Lee I, Chung K, Chung JM. Oxidative stress in the spinal cord is an important contributor in capsaicin-induced mechanical secondary hyperalgesia in mice. Pain. 2008;138:514-524.

42. McGrath C, Tallman K, Porter N, Marnett LJ. Structure-activity analysis of diffusible lipid electrophiles associated with phospholipid peroxidation: 4-hydroxynonenal and 4-oxononenal analogues. Chem Res Toxicol. 2011;24:357-370.

43. Rossato MF, Velloso NA, de Oliveira Ferreira AP, de Mello CF, Ferreira J. Spinal levels of nonprotein thiols are related to nociception in mice. J Pain. 2010;11:545-554.

44. Lerea L, Carlson N, Simonato M, Morrow J, Roberts J, Mcnamara JO. Prostaglandin F2alpha is required for NMDA receptor-mediated induction of c-fos mRNA in dentate gyrus neurons. J Neurosci. 1997;17:117-124.

45. Nickel JC. The Prostatitis Manual. Oxfordshire (UK): Bladon Medical Publishing; 2002. 


\section{Supplementary materials}

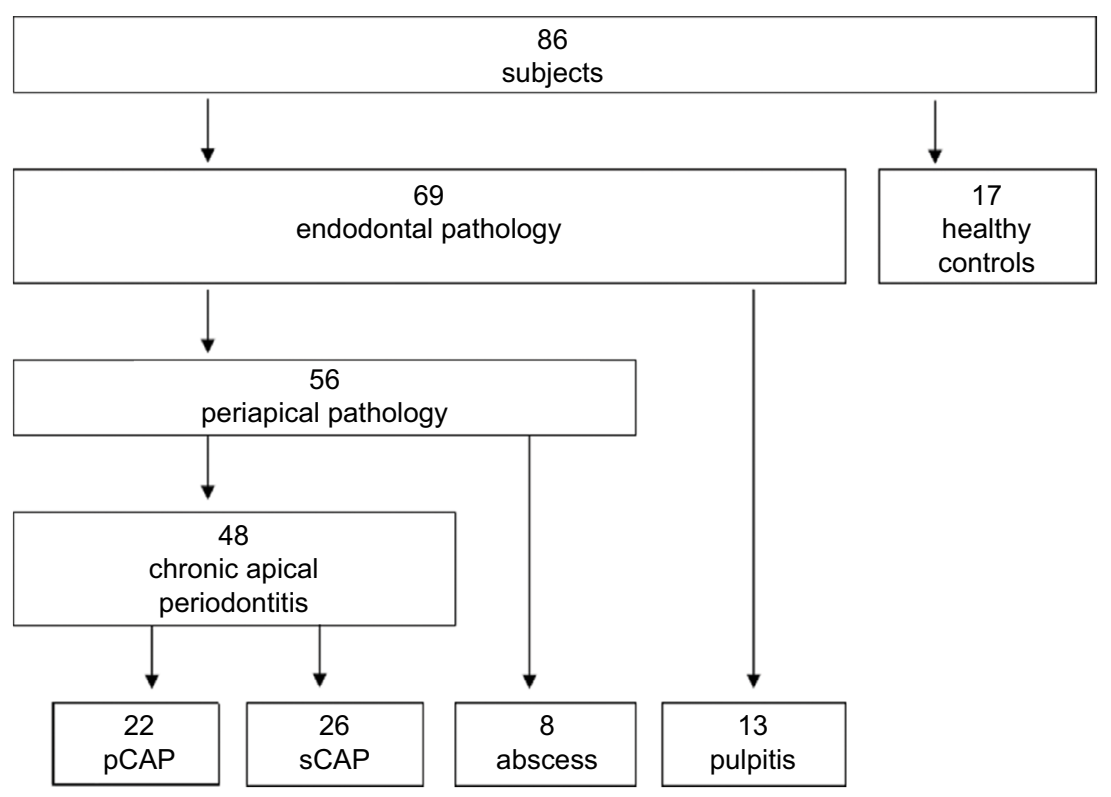

Figure SI Overview of study subjects.

Abbreviations: PCAP, primary chronic apical periodontitis; sCAP, secondary chronic apical periodontitis.

Table SI Inclusion and exclusion criteria for study subjects

\begin{tabular}{|c|c|c|c|c|}
\hline pCAP group & sCAP group & Pulpitis group & Abscess group & Control group \\
\hline \multicolumn{5}{|l|}{ Inclusion criteria } \\
\hline Age at least 10 years & Age at least 10 years & Age at least 10 years & Age at least 10 years & Age at least 10 years \\
\hline $\begin{array}{l}\text { Tooth with AP lesion } \\
\text { without RCF }\end{array}$ & $\begin{array}{l}\text { Tooth with AP lesion with } \\
\text { RCF }\end{array}$ & Tooth without AP lesion & Tooth with AP lesion & Excellent oral health \\
\hline $\begin{array}{l}\text { Objective and subjective } \\
\text { criteria for AP }\end{array}$ & $\begin{array}{l}\text { Objective and subjective } \\
\text { criteria for AP }\end{array}$ & $\begin{array}{l}\text { Objective and subjective } \\
\text { criteria for pulpitis }\end{array}$ & $\begin{array}{l}\text { Objective and subjective } \\
\text { criteria for abscess of } \\
\text { endodontic origin }\end{array}$ & Excellent oral hygiene \\
\hline $\begin{array}{l}\text { Lesion on X-ray with } \\
\text { PAI }>2\end{array}$ & $\begin{array}{l}\text { Lesion on X-ray with } \\
\text { PAI }>2\end{array}$ & $\begin{array}{l}\text { No lesion on X-ray } \\
(\mathrm{PAl}<2)\end{array}$ & $\begin{array}{l}\text { Lesion on X-ray with } \\
\mathrm{PAI}>2\end{array}$ & Intact teeth \\
\hline $\begin{array}{l}\text { Excellent general health } \\
\text { Exclusion criteria }\end{array}$ & Excellent general health & Excellent general health & Good general health & Excellent general health \\
\hline Age $<10$ years & Age $<10$ years & Age $<10$ years & Age $<10$ years & Age $<10$ years \\
\hline Diseased primary teeth & Diseased primary teeth & Diseased primary teeth & Diseased primary teeth & Bad oral hygiene \\
\hline Vertical root fracture & Vertical root fracture & Vertical root fracture & Vertical root fracture & Any kind of tooth disease \\
\hline Horizontal root fracture & Horizontal root fracture & Horizontal root fracture & Horizontal root fracture & $\begin{array}{l}\text { Any kind of gingival or } \\
\text { periodontal disease }\end{array}$ \\
\hline $\begin{array}{l}\text { Tooth with endo-perio } \\
\text { lesion }\end{array}$ & $\begin{array}{l}\text { Tooth with endo-perio } \\
\text { lesion }\end{array}$ & $\begin{array}{l}\text { Tooth with endo-perio } \\
\text { lesion }\end{array}$ & $\begin{array}{l}\text { Tooth with endo-perio } \\
\text { lesion }\end{array}$ & Restored teeth \\
\hline $\begin{array}{l}\text { Tooth with peri-endo } \\
\text { lesion }\end{array}$ & $\begin{array}{l}\text { Tooth with peri-endo } \\
\text { lesion }\end{array}$ & $\begin{array}{l}\text { Tooth with peri-endo } \\
\text { lesion }\end{array}$ & $\begin{array}{l}\text { Tooth with peri-endo } \\
\text { lesion }\end{array}$ & $\begin{array}{l}\text { Any kind of general acute } \\
\text { disease }\end{array}$ \\
\hline $\begin{array}{l}\text { Other conditions and } \\
\text { clinical situations that } \\
\text { require RCT }\end{array}$ & $\begin{array}{l}\text { Other conditions and } \\
\text { clinical situations that } \\
\text { require RCT }\end{array}$ & $\begin{array}{l}\text { Other conditions and } \\
\text { clinical situations that } \\
\text { require RCT }\end{array}$ & $\begin{array}{l}\text { Other conditions and } \\
\text { clinical situations that } \\
\text { require RCT }\end{array}$ & $\begin{array}{l}\text { Any kind of chronic general } \\
\text { disease }\end{array}$ \\
\hline $\begin{array}{l}\text { Tooth with gingival pocket } \\
>3.5 \mathrm{~mm}\end{array}$ & $\begin{array}{l}\text { Tooth with gingival pocket } \\
>3.5 \mathrm{~mm}\end{array}$ & $\begin{array}{l}\text { Tooth with gingival pocket } \\
>3.5 \mathrm{~mm}\end{array}$ & $\begin{array}{l}\text { Tooth with gingival pocket } \\
>3.5 \mathrm{~mm}\end{array}$ & $\begin{array}{l}\text { Any kind of infectious disease } \\
\text { in present or past history }\end{array}$ \\
\hline
\end{tabular}

(Continued) 
Table SI (Continued)

\begin{tabular}{|c|c|c|c|c|}
\hline pCAP group & sCAP group & Pulpitis group & Abscess group & Control group \\
\hline Unrestorable tooth & Unrestorable tooth & Unrestorable tooth & Unrestorable tooth & \\
\hline (deeply fractured or highly & (deeply fractured or highly & (deeply fractured or highly & (deeply fractured or highly & \\
\hline carious tooth which is & carious tooth which is & carious tooth which is & carious tooth which is & \\
\hline impossible to restore & impossible to restore & impossible to restore & impossible to restore & \\
\hline and therefore must be & and therefore must be & and therefore must be & and therefore must be & \\
\hline extracted) & extracted) & extracted) & extracted) & \\
\hline Tooth that has undergone & Tooth that has undergone & & Tooth that has undergone & \\
\hline apical surgery with or & apical surgery with or & & apical surgery with or & \\
\hline without retrograde filling & without retrograde filling & & without retrograde filling & \\
\hline $\begin{array}{l}\text { Any type of smoking or } \\
\text { tobacco abuse }\end{array}$ & $\begin{array}{l}\text { Any type of smoking or } \\
\text { tobacco abuse }\end{array}$ & $\begin{array}{l}\text { Any type of smoking or } \\
\text { tobacco abuse }\end{array}$ & $\begin{array}{l}\text { Any type of smoking or } \\
\text { tobacco abuse }\end{array}$ & $\begin{array}{l}\text { Any type of smoking or } \\
\text { tobacco abuse }\end{array}$ \\
\hline Antibiotic or any other & Antibiotic or any other & Antibiotic or any other & Antibiotic or any other & Antibiotic or any other \\
\hline medicament usage in & medicament usage in & medicament usage in & medicament usage in & medicament usage in previous \\
\hline previous 3 months & previous 3 months & previous 3 months & previous 3 months & 6 months \\
\hline Diabetes I or II & Diabetes I or II & Diabetes I or II & Diabetes I or II & Diabetes I or II \\
\hline Immune suppressed & Immune suppressed & Immune suppressed & & Immune suppressed person \\
\hline person (HIV, AIDS, & person (HIV, AIDS, & person (HIV, AIDS, & & (HIV, AIDS, chemotherapy) \\
\hline chemotherapy) & chemotherapy) & chemotherapy) & & \\
\hline
\end{tabular}

Abbreviations: HIV, human immunodeficiency virus; AIDS, acquired immunodeficiency syndrome; pCAP, primary chronic apical periodontitis; sCAP, secondary chronic apical periodontitis; AP, apical periodontitis; RCF, root canal filling; RCT, root canal treatment; PAI, periapical index.

\section{Publish your work in this journal}

The Journal of Pain Research is an international, peer reviewed, open access, online journal that welcomes laboratory and clinical findings in the fields of pain research and the prevention and management of pain. Original research, reviews, symposium reports, hypothesis formation and commentaries are all considered for publication.

\section{Dovepress}

The manuscript management system is completely online and includes a very quick and fair peer-review system, which is all easy to use. Visit http://www.dovepress.com/testimonials.php to read real quotes from published authors. 